\title{
Vertebroplasty Using Calcium Phosphate Cement for Osteoporotic Vertebral Fractures: Study of Outcomes at a Minimum Follow-up of Two Years
}

\author{
Masato Nakano, Norikazu Hirano², Mineyuki Zukawa', Kayo Suzuki', \\ Jinichiro Hirose ${ }^{3}$, Tomoatsu Kimura ${ }^{1}$, Yoshiharu Kawaguchi ${ }^{1}$ \\ ${ }^{1}$ Department of Orthopaedic Surgery, Faculty of Medicine, University of Toyama, Toyama, Japan \\ ${ }^{2}$ Department of Orthopaedic Surgery, Toyama Rosai Hospital, Toyama, Japan \\ ${ }^{3}$ Department of Radiology, Toyama Rosai Hospital, Toyama, Japan
}

Study Design: A case-series study.

Purpose: To assess the long-term clinical and radiographic outcomes after vertebroplasty using calcium phosphate cement (CPC) for treatment of osteoporotic vertebral fractures (OVF).

Overview of Literature: Vertebroplasty has become common for the treatment of OVF. However, few studies have reported the clinical application of CPC to vertebroplasty.

Methods: We reviewed 86 consecutive patients undergoing 99 vertebroplasties using CPC. Following repositioning and curettage of the pathological soft tissue of the vertebral body (VB), vertebroplasty using CPC was performed in patients with osteoporotic burst fracture and pseudoarthrosis (procedure A). Vertebroplasty was also performed in patients with osteoporotic compression fractures (procedure B). Back pain and lower back pain were evaluated using the visual analogue scale (VAS). The VB deformity index was measured in a lateral radiograph as the ratio of the VBs height to its longitudinal diameter.

Results: The mean age at time of surgery was 77 years old. The mean duration of follow-up was forty-four months. All patients reported decreased pain according to the VAS immediately after vertebroplasty, and pain relief was maintained at the last follow-up in all patients without new OVFs. Complete bone union was observed in all cases by six months after surgery. The mean recovery rate of deformity index was $5.9 \%$ in procedure $\mathrm{A}$ and $0.02 \%$ in procedure B at the final follow-up visit.

Conclusions: Vertebroplasty using CPC gave a satisfactory outcome and no delayed complications in elderly patients with osteoporotic vertebral fractures at follow-up times of at least two years.

Key Words: Osteoporosis, Vertebral fracture, Biodegradable bone cement substitutes, Calcium phosphate cement, Vertebroplasty

\section{Introduction}

Vertebroplasty, the augmentation of the vertebral body (VB) by percutaneous polymethylmethacrylate (PMMA) injection, results in good enhancement of VB strength and pain relief for osteoporotic vertebral fractures (OVF) [13]. A number of biodegradable bone cement substitutes which might be thought of as alternatives for PMMA have been developed and biomechanically tested [4,5]; however, none were readily available for use in the spine.

Received Apr 14, 2011; Revised May 25, 2011; Accepted Jun 27, 2011

Corresponding author: Masato Nakano, MD, PhD

Department of Orthopaedic Surgery, Faculty of Medicine, University of Toyama,

2630 Sugitani, Toyama 930-0194, Japan

Tel: +81-764-34-7353, Fax: +81-764-34-5035, E-mail: mnakano-tym@umin.ac.jp 
One of these substitutes, calcium phosphate cement (CPC), was developed in 1993; it can be mixed into an injectable paste and is self-setting, radiopaque, biocompatible, biodegradable, and osteoconductive [6-8]. It tends to be resorbed progressively from the outer surface and replaced by bone tissue during the normal bone remodeling process $[9,10]$. CPC has been proven to be useful in VB augmentation in patients with osteoporosis [9-11] and has been available for clinical use in the spine since 2000 [10]. In previous clinical studies, percutaneous transpedicular vertebroplasty using $\mathrm{CPC}$ was found to be a minimally invasive procedure that provided pain relief $[9,12]$. However, vertebroplasty using CPC has invoked both enthusiasm and controversy, in part because the handling characteristics differ from those of PMMA, resulting in some correction loss of the VB $[9,12,13]$, and few studies have reported the results of a long-term follow-up. The object of this prospective study was to assess the clinical outcome of vertebroplasty using CPC for OVF after a minimum follow-up duration of two years and to discuss the technical points of the clinical application of CPC for vertebroplasty.

\section{Materials and Methods}

We reviewed 106 consecutive patients undergoing 123 vertebroplasty procedures using CPC between July 2000 and October 2003. All of the patients were admitted with thoracic, thoracolumbar, or lumbar vertebral fractures due to osteoporosis. The inclusion criteria included painful OVF matched with radiographic findings. In the assessment of these patients, the location of osteoporotic vertebral fractures was diagnosed by radiography and magnetic resonance imaging. The other inclusion criteria were the presence of osteoporosis as diagnosed by radiography and/or bone mineral density based on the Clinical Practice Guideline of the Japanese Osteoporosis Society [14] and a minimum age of sixty years. Exclusionary criteria included pathologic fracture due to myeloma/metastasis and osteomyelitis, coagulopathy, a neurological deficit related to the fracture, and multilevel OVFs over three levels. The human research ethics committee at our hospital approved the study, and all participants provided written informed content.

We selected two procedures [9]: 1) Following repositioning and curettage of the pathological soft tissues of the VB,

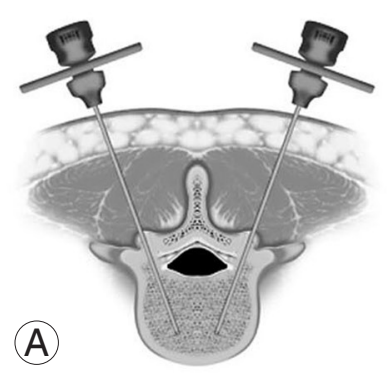

(A)

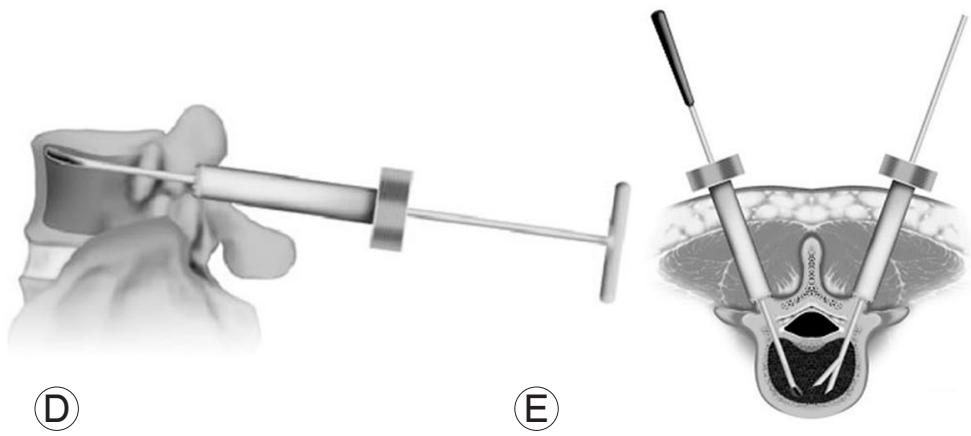

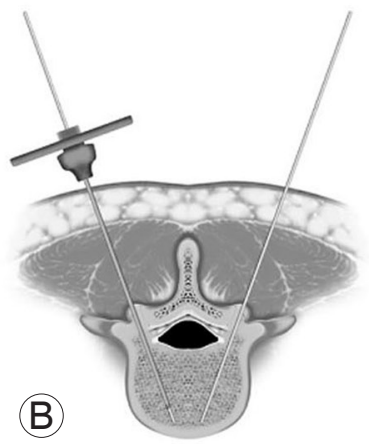

(C)

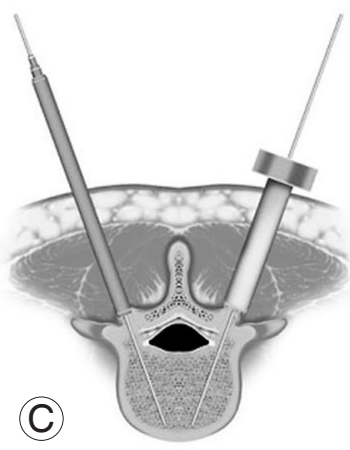

(F)

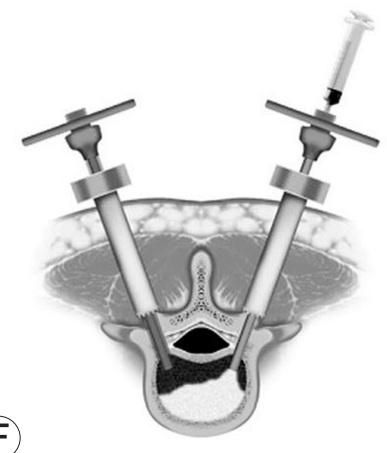

Fig. 1. Diagrams depicting the steps of the percutaneous vertebroplasty procedure using calcium phosphate cement (CPC). (A) Two Jamshidi needles are inserted percutaneously and transpedicularly under fluoroscopic guidance. (B) Guide pins (1.5-mm diameter) are inserted through the needles. (C) Two portals are set on the bilateral laminae after dilating using the dilators. (D, E) Debridement of the pathologic tissues in the vertebral body and reduction are performed using rongeurs, curettes, probes, and a urinary balloon. (F) Finally, CPC injection and filling are performed after injection of the contrast media and washing with saline. 
vertebroplasty using CPC (Biopex, Pentax, Tokyo, Japan) was performed in patients with osteoporotic burst fracture and pseudoarthrosis (procedure A) (Figs. 1 and 2). 2) Vertebroplasty was also performed in patients with osteoporotic compression fractures (procedure B). The selection criteria for procedure A included computed tomography (CT) scanning evidence of a posterior wall fracture of the VB with displacement and bulging of more than $2 \mathrm{~mm}$ and/ or presentation more than eight weeks after the time of the injury. Those for procedure B included both CT scanning evidence of posterior wall fracture of VB with displacement and bulging of less than $2 \mathrm{~mm}$, and presentation fewer than eight weeks after the time of the injury.
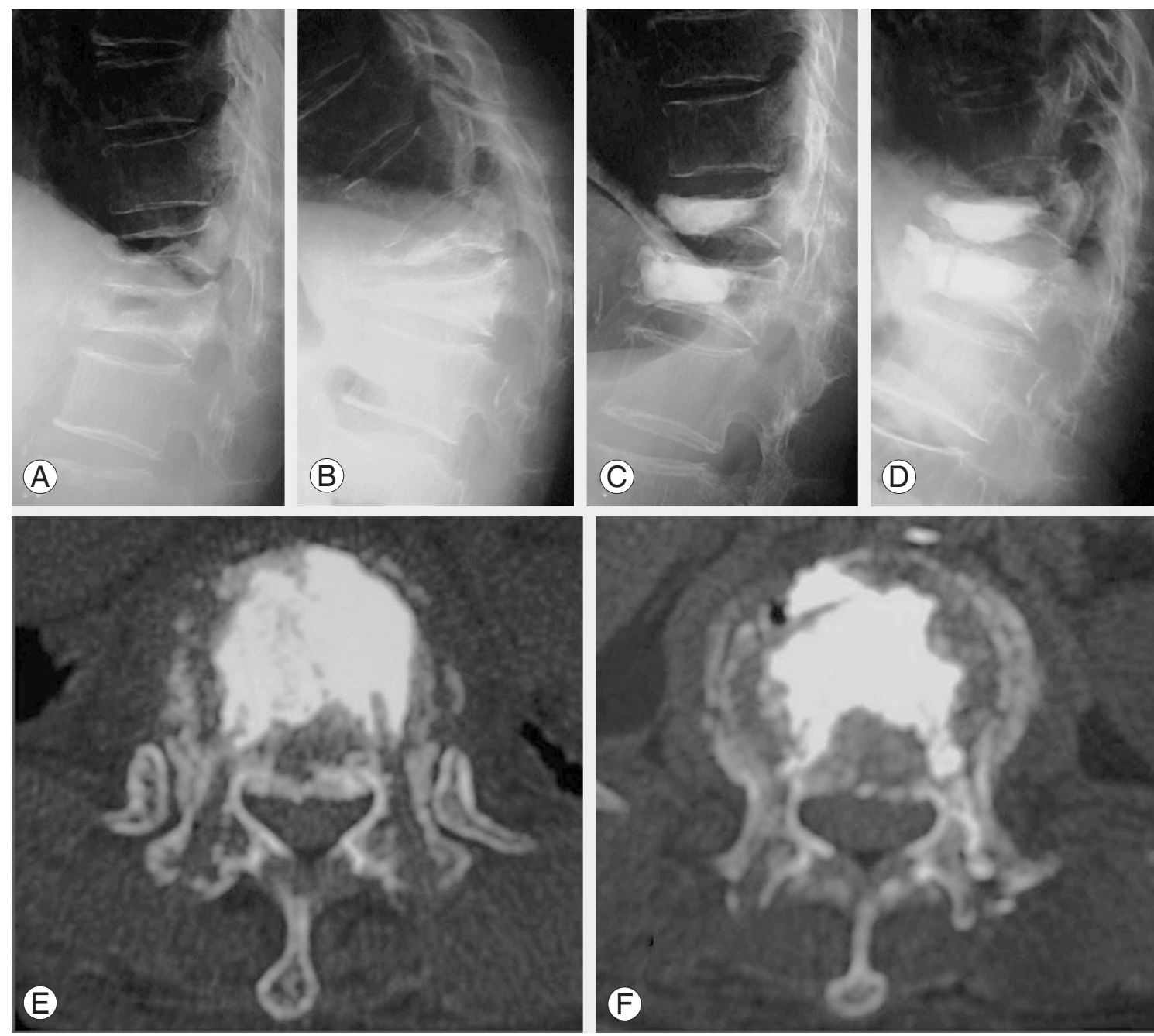

Fig. 2. Representative radiographs and computed tomography (CT) findings demonstrating a typical example of pseudoarthrosis following osteoporotic compression fracture. (A, B) Preoperative flexion-extension lateral radiographs demonstrating significant instability and kyphotic deformity of the vertebral body at T12 and L1. (C) A postoperative radiograph obtained immediately after procedure A revealing excellent augmentation of the vertebral body and significant correction of the kyphotic deformity of $30^{\circ}$ in the Cobb measurement. (D) At 3 months after surgery, the correction is relatively decreased because the CPC mass was partially broken and displaced anteriorly. (E, F) A postoperative CT finding obtained one week after surgery demonstrating the preoperative defect filled with calcium phosphate cement at T12 (E) and L1 (F). 
impactors, and probes (Fig. 1D and 1E). A preparation of CPC with a powder/liquid ratio of 2.8 to 3.6 is used two minutes after mixing [6-11]. After intra-vertebral injection of the contrast media and washing with saline, CPC injection and filling are performed using 8-gauge Jamshidi needles and 1-ml syringes (Fig. 1F). All of these techniques are performed with the aid of fluoroscopic guidance.

In procedure $\mathrm{B}$, in-situ $\mathrm{CPC}$ injection is performed after induction of local anesthesia. This procedure was performed in the same manner as previously reported for percutaneous vertebroplasty using PMMA $[2,3]$. Two Jamshidi needles are inserted percutaneously and transpedicularly with the aid of fluoroscopic guidance. The CPC powder/liquid ratio is 2.6 to 3.0 [6-11]. Postoperatively, in both groups (procedure A and B), ambulation was initiated on Day 7 after operation when the compressive strength of CPC (Biopex) reached its maximum.

Back pain and lower-back pain were evaluated using the visual analogue scale (VAS, 0 to $100 \mathrm{~mm}$ ) [15] and the duration of analgesic medication requirement. The evaluation of pain in patients who suffered newly developed fractures of other VB was discontinued. Walking ability was classified into four grades: grade I, the patient cannot walk and needs a wheel chair; grade II, the patient can only walk using a walker; grade III, the patient can walk using a stick or a crutch; and grade IV, the patient can walk without a stick. To evaluate VB deformity, the deformity index was measured on a lateral radiograph as the ratio of VB height (sum of measurements at anterior, middle, and posterior regions) to its longitudinal diameter (Fig. 3) $[9,12]$. The kyphosis rate of the VB was expressed as the percentage of VB height at the anterior region to its height at the posterior region. Each outcome was obtained before surgery and daily up to two weeks (with VAS score), at 1, 2, 3, 6, 12 and 24 months postoperatively, and at the final follow-up visit.

To evaluate changes from pre- to postoperative status in VAS score, the deformity index, and the kyphosis rate of the VB, statistical analyses were performed using the paired $t$-test. Variables were corrected for baseline values by subtracting the follow-up measurement from the baseline value and expressing the difference as a percentage of the baseline value. A probability value of less than 0.05 was accepted as the level of statistical significance.

\section{Results}

Procedure A was applied to forty-one patients with thirty- eight osteoporotic burst fractures (two at T9, one at T11, ten at T-12, seven at L-1, seven at L-2, two at L-3, seven at L-4, and two at L-5) and with twelve pseudoarthroses or late collapse (four at T-12, two at L-1, two at L-2, and four at L-4). Procedure B was applied to sixty-five patients with osteoporotic vertebral compression fractures (one at T-6, two at $\mathrm{T}-8$, two at $\mathrm{T}-9$, three at $\mathrm{T}-10$, four at $\mathrm{T}-11$, fifteen at $\mathrm{T}-12$, twenty-three at L-1, eight at L-2, eight at L-3, four at L-4, and three at L-5). The mean interval from injury to surgery in Procedure A was 43.6 days (range, 6 to 270 days), and in Procedure B it was 17.7 days (range, 3 to 56 days).

Eight patients $(9.3 \%)$ died after less than two years follow-up as a result of causes that were unrelated to the vertebroplasty, and twelve patients (11.3\%) were lost to followup. Thus, eighty-six patients (twenty-two men and sixtyfour women) (99 VBs) had a minimum of two years of follow-up. The mean duration of follow-up was 44 months (range, 24 to 60 months). The mean age at time of surgery was 77 years old (range, 60 to 95 years).

The VAS score could be assessed in 75 patients. The patients who underwent procedure A suffered from intractable pain preoperatively, which had been unresolved by nonoperative care. The mean preoperative VAS was $87.6 \mathrm{~mm}$ (range, 60 to $100 \mathrm{~mm}$ ). The mean VAS score immediately after surgery was decreased to $50 \mathrm{~mm}$ (range, 20 to $80 \mathrm{~mm} ; p<0.0001)$. The mean VAS after ambulation initiation was $30 \mathrm{~mm}$ (range, 10 to $50 \mathrm{~mm} ; p<0.0001$ ). The mean VAS scores were $9.6 \mathrm{~mm}, 9.5 \mathrm{~mm}$, and $7.4 \mathrm{~mm}$ at the 6- and 12-month follow-up examinations and at the final follow-up visit (range, 24 to 60 months), respectively $(p<0.0001)$. The patients who underwent procedure B also

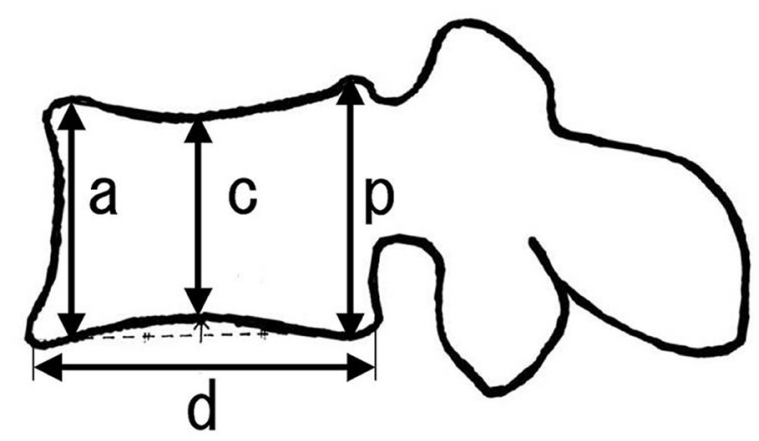

Fig. 3. A scheme for evaluating the sagittal-plane correction of the vertebral body (VB) deformity on a lateral radiograph taken in the neutral decubitus position $[10,13,15]$. The deformity index $=(a+c+p) / d$; this index analyzes the deformity of the VB. The kyphosis rate $(\%)=100 \times \mathrm{a} / \mathrm{p}$; this measures the kyphotic deformity of the VB. 
suffered from intractable pain preoperatively; the mean preoperative VAS score was $85 \mathrm{~mm}$ (range, 50 to $100 \mathrm{~mm}$ ). The mean VAS score immediately after surgery decreased to $36.8 \mathrm{~mm}$ (range, 10 to $70 \mathrm{~mm} ; p<0.0001$ ). The mean VAS after ambulation initiation was $23.3 \mathrm{~mm}$ (range, 0 to $50 \mathrm{~mm} ; p<0.0001)$. The mean VAS scores were $5.2 \mathrm{~mm}$, $3.3 \mathrm{~mm}$, and $3.3 \mathrm{~mm}$ at the six and twelve-month followup examination and at the final follow-up visit (range, 24 to 60 months), respectively $(p<0.0001)$. The mean VAS score immediately after surgery was decreased to $42 \mathrm{~mm}$ from $86.2 \mathrm{~mm}(p<0.0001)$. In all patients without new OVFs, pain relief was maintained at the last follow-up. The mean duration of analgesic medication requirement in patients who underwent procedures A and B were $22.7 \pm 85.8$ days and $14.6 \pm 30.5$ days, respectively.

Walking ability decreased by more than one grade in 9 of 86 patients $(10.5 \%)$ at the 12 -month follow-up examination as compared with the ability before injury, from grade IV to grade III in 2 cases of procedure A and 3 cases of procedure $\mathrm{B}$, from grade IV to grade II in one case of procedure A and 2 cases of procedure B, and from grade III to grade II in one case of procedure B. Walking ability was preserved in 77 patients $(89.5 \%)$, and it was improved from grade II to grade III in 3 cases, from grade I to grade III in one case, and from grade I to grade IV in one case. The mean grade of walking ability was 3.43 in procedure A and 2.95 in procedure B before injury, which changed to 3.25 and 2.94, respectively, at the 12-month follow-up examination.

The mean amount of CPC injected into each individual was $6.5 \mathrm{ml}$ (range, 2.5 to $10 \mathrm{ml}$ ) for procedure A and $3.9 \mathrm{ml}$ (range, 1 to $6.5 \mathrm{ml}$ ) for procedure B. The mean operative times for procedures A and B were 62.1 minutes (range, 32 to 100 minutes) and 26.4 minutes (range, 15 to 47 minutes), respectively. The mean amount of intraoperative blood loss in procedure $A$ was $21 \mathrm{~g} \mathrm{(} \mathrm{n}=6$; range, 10 to $30 \mathrm{~g}$ : It was too insignificant to count in the other cases), and the blood loss in procedure B was too insignificant to count in all cases.

The mean preoperative VB deformity index was 1.57 in procedure $\mathrm{A}$ and 1.73 in procedure $\mathrm{B}$, which improved to 1.75 and 1.88 , respectively, just after surgery $(p<0.0001$ and $p<0.0001$, respectively). At the final follow-up visit (range, 24 to 60 months), the mean deformity index was 1.62 in procedure $\mathrm{A}$ and 1.72 in procedure $\mathrm{B}(p=0.084$ and $p=$ 0.6763 , respectively). The mean recovery rate of deformity index was $5.9 \%$ in procedure $A$ and $0.02 \%$ in procedure $\mathrm{B}$.

The mean preoperative kyphosis rate of the fractured VB was $75.6 \%$ in procedure A and $75.3 \%$ in procedure B, which improved to $88.7 \%$ and $86.4 \%$, respectively, just after surgery ( $p<0.0001$ and $p<0.0001$, respectively). At the final follow-up visit, the mean kyphosis rate was $79.3 \%$ in procedure $\mathrm{A}$ and $76.4 \%$ in procedure $\mathrm{B}(p=0.1935$ and $p=0.4446$, respectively), and the mean recovery rate was $10.5 \%$ in procedure A and $2.5 \%$ in procedure B. Satisfactory bone union was demonstrated on CT or sagittal tomographic images in all cases until 6 months after surgery. The injected CPC gradually tended to disappear and be replaced by newly developed bone as demonstrated on $\mathrm{CT}$ images at $3,6,12,24$, and/or 36 months after surgery in all patients who underwent this modality (Fig. 4). The degradation of the CPC mass was observed only in the interface to the
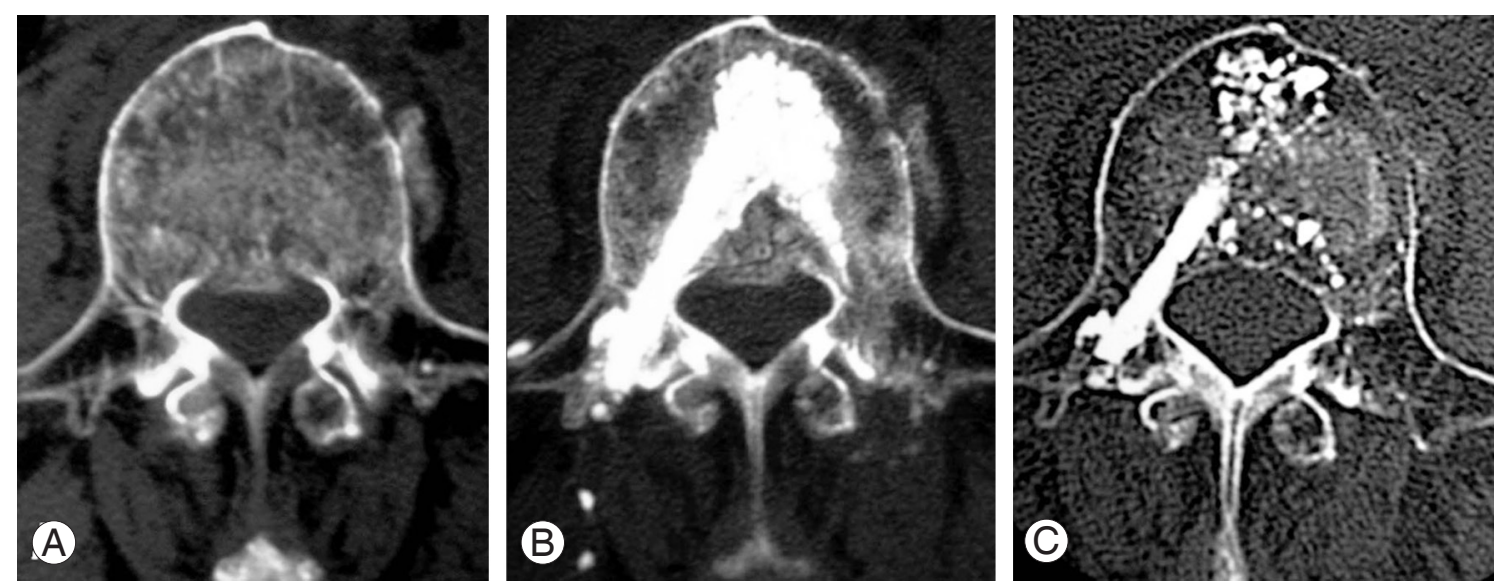

Fig. 4. Computed tomography (CT) studies demonstrating an example of osteoporotic burst fracture at L3. A preoperative CT (A) demonstrating the fracture line from the anterior to middle column including a posterior wall fracture of the vertebral body with displacement and bulging at 30 days after injury. A postoperative CT obtained 1 week after procedure B (B), demonstrating the preoperative defect filled with calcium phosphate cement. At the 3-years follow-up, the injected calcium phosphate cement is partially absorbed and replaced by newly formed bone, and the fragment of fractured posterior wall is remodeled in the spinal canal (C). 
Table 1. Incidence of cement leakage

\begin{tabular}{cll}
\hline \hline Cement leak $(\%)$ & Technique, disease & Author (year) \\
\hline 37.5 & Vertebroplasty-PMMA, malignant tumor & Cotten et al. (1996) [21] \\
65 & Vertebroplasty-PMMA, OVF & Cortet et al. (1999) [2] \\
40.3 & Vertebroplasty-PMMA, OVF & Ryu et al. (2002) [20] \\
7.8 & Vertebroplasty-CPC, OVF & Nakano et al. (2005) [13] \\
8.6 & Kyphoplasty-PMMA, OVF & Lieberman et al. (2001) [22] \\
9 & Kyphoplasty-PMMA, OVF, malignant tumor & Ledlie and Renfo (2003) [23] \\
8.7 & Vertebroplasty-CPC following intravertebral operation & Nakano et al. (2005) [13]
\end{tabular}

PMMA: Polymethylmethacrylate, OVF: Osteoporotic vertebral fracture, CPC: Calcium phosphate cement.

bone, and the hydroxyapatite mass was preserved in the VB. A greater than $10 \%$ decrease in the VB deformity index was seen at the final examination compared with the value immediately after surgery in 28 of 99 VBs and less than $50 \%$ for the kyphosis rate at the last follow-up in 8 of $99 \mathrm{VBs}$.

One patient suffered from temporary respiratory insufficiency during the $\mathrm{CPC}$ injection in procedure B $(0.9 \%)$. In this patient, there was no evidence of a pulmonary embolism induced by CPC on postoperative lung $\mathrm{CT}$ image and radiograph. There was a small amount of CPC leakage into the spinal canal in seven cases (6.6\%), into the intervertebral disc in seven cases $(6.6 \%)$, and into the paravertebral muscle in one $(0.9 \%)$; however, no patients presented with neurological abnormalities or infection or required revision surgery.

Twenty-one newly developed vertebral fractures were seen, including eight vertebral fractures at an adjacent level (9.3\%). Although no pulmonary embolisms were observed, a deep venous thrombosis was diagnosed in one patient. Two patients suffered from urinary tract infections, and one patient suffered with ileus.

\section{Discussion}

Vertebroplasty for OVF is a minimally invasive procedure and effective for the relief of intractable pain as shown in previous studies [2,9]. Although two multicenter, randomized-controlled studies showed that improvement in pain and pain-related disability associated with osteoporotic compression fractures in patients treated with vertebroplasty were similar to improvement in a sham operation group, they included patients with acute vertebral fractures, which might expect to be a good prognosis in a conservative treatment $[16,17]$. In these studies, they only reported the short-term clinical outcome up to 6 months after treatment and did not perform radiological assessment. In spite of these two studies, one controversial study reported that kyphoplasty is an effective and safe procedure for treatment in patients with acute vertebral fractures compared with conservative treatment [18]. These above studies used PMMA for both vertebroplasty and kyphoplasty. In this present study, we are the first to demonstrate that the clinical application of CPC for vertebroplasty is effective and safe in a long follow-up period in a minimum or 2 years after treatment. We also showed radiological recovery after vertebroplasty.

One of the biodegradable bone cement substitutes, CPC, can be mixed into an injectable paste like PMMA. In a study using cadavers, CPC augmented the vertebral strength as compared with intact vertebral bodies at 10 days after injection [11]. At present, in the second generation of CPC (Biopex-R), the maximum compressive strength is $80 \mathrm{MPa}$ in 72 hours after mixing powder with liquid, which is strong enough to reinforce the osteoporotic vertebral body. As the compressive strength of CPC ( $80 \mathrm{MPa})$ is lower than that of PMMA (99 MPa) [6-8,19], vertebroplasty using PMMA may provide a better radiological result than that using CPC for OVF. Although CPC has the same risk associated with cement extrusion, we prefer CPC to PMMA especially for younger patients with osteoporotic vertebral fractures because CPC is more biocompatible, more biodegradable, more osteoconductive, and may be safer than PMMA.

Vertebroplasty using CPC invokes controversy, in part because of the handling characteristics that differ from those of PMMA, including cost, performance, and the long hardening time. Because CPC is more difficult to inject under high local pressure than PMMA, a bilateral approach through the bilateral pedicles and cavity formation of the VB before vertebroplasty might be necessary. Although new devices and materials for vertebroplasty and kyphoplasty 
Table 2. Subsequent adjacent vertebral fracture after kyphoplasty and vertebroplasty

\begin{tabular}{lcc}
\hline \hline Fracture rate (\%) & Follow up (mo) & Author (year) \\
\hline Untreated OVCF & 12 & Lindsay et al. (2001) [24] \\
19.2 & 6 & Kasperk et al. (2005) [25] \\
12 & & Grados et al. (2000) [26] \\
Vertebroplasty & 48 & Uppin et al. (2003) [27] \\
52 & 24 & B: Vertebroplasty-CPC \\
8.3 & 24 & \\
7.8 & 6 & Kasperk et al. (2005) [25] \\
Kyphoplasty & 12 & Ledlie and Rendo (2003) [23] \\
6 & 18 & Fribourg et al. (2004) [28] \\
5.2 & 24 & A: Vertebroplasty-CPC following intravertebral operation \\
28 & &
\end{tabular}

OVCF: Osteoporotic vertebral compression fracture, CPC: Calcium phosphate cement, A: Procedure A in this study, B: Procedure A in this study.

can be developed in the future, for the present, our findings in the current study suggest vertebroplasty following repositioning and curettage of the pathological soft tissues of the VB (procedure A in this study) is one of the best effective and safe procedures for the clinical application of $\mathrm{CPC}$ in the treatment of osteoporotic vertebral fractures, including burst type fractures, pseudoarthroses, and late collapse .

Initially, the height of the VB and kyphosis rates improved significantly for both treatment groups in this study. However, this improvement was lost with the passage of time. In our experiences, mixing blood with CPC could result in fragmentation of the $\mathrm{CPC}$ mass and subsequent loss of correction [9]. Control of bleeding from the VB during the procedure is important for this reason. In the second generation of CPC (Biopex-R), the fragmentation incidence of the $\mathrm{CPC}$ mass due to mixing with blood is decreasing. At least we can speculate that it is important to use a larger amount and a higher powder/liquid ratio of the injected CPC to achieve good correction. On the other hand, we recommend that the injection amount should be kept at less than $9 \mathrm{ml}$ for thoraco-lumbar lesions, and the powder/ liquid ratio of CPC (Biopex) should be kept at higher than 2.7 (more than 3.4 with Biopex-R) because an excessive amount and an excessively low powder/liquid ratio of CPC may increase the risk of leakage and embolism.

While the incidence of cement leakage following vertebroplasty using PMMA is $40 \%$ to $65 \%$, that following in-situ vertebroplasty using $\mathrm{CPC}$ was $7.8 \%$ in a previous study (Table 1) [2,13,20-23]. A low rate of CPC leakage may be due to the patient selection for the two procedures: vertebroplasty and vertebroplasty following repositioning and curettage of the pathological soft tissues. Regarding new vertebral fractures at an adjacent level after vertebroplasty and kyphoplasty using PMMA and CPC in the literature, the fracture rate in this study using CPC was not high as compared with that in vertebroplasty and kyphoplasty using PMMA or with the use of conservative treatment, although the indication and follow-up periods were different (Table 2) [23-28]. While ambulation was initiated at postoperative 7 days after CPC injection in this study, ambulation could be started right after PMMA injection. Although the maximum compressive strength is $80 \mathrm{MPa}$ in 72 hours after injection of second-generation CPC (Biopex-R), bed rest for over 3 days may lead to other complications, such as deep vein thrombosis and bed sores, in addition to a decrease in the patient's satisfaction. It also requires longer hospitalization and is costlier. In addition, CPC itself is more expensive than PMMA.

Study limitations include the fact that there were not any control groups. Recently, in the prospective cohort study, no statistically significant differences were observed between the other type of CPC and PMMA-cement in balloonkyphoplasty for patients with painful osteoporotic vertebral fractures regarding VAS-scores, mobility-scores, or heightrestoration; in addition, no significant difference in the occurrence of vertebral follow-up fractures were noted between the groups [29]. To compare CPC with PMMA 
and to compare vertebroplasty with kyphoplasty, it will be necessary to perform randomized, controlled trials.

\section{Conclusions}

Based on carefully selected patients and only using the appropriate amount and powder/liquid ratio of injected calcium phosphate cement, vertebroplasty using CPC prevented the VB from late collapse and pseudoarthrosis and gave a satisfactory outcome excepting relatively long bed rest in patients with OVF after long-term follow-up.

\section{Acknowledgements}

No benefits in any form have been received or will be received from a commercial party related directly or indirectly to the subject of this article. This work was supported in part by a Grant-in-Aid for Scientific Research (2000-2002 \#1) from Toyama Rosai Hospital and Labour Welfare Corporation.

\section{REFERENCES}

1. Galibert P, Deramond H, Rosat P, Le Gars D. Preliminary note on the treatment of vertebral angioma by percutaneous acrylic vertebroplasty. Neurochirurgie 1987;33:166-8.

2. Cortet B, Cotten A, Boutry N, et al. Percutaneous vertebroplasty in the treatment of osteoporotic vertebral compression fractures: an open prospective study. J Rheumatol 1999;26:2222-8.

3. Deramond H, Depriester C, Galibert P, Le Gars D. Percutaneous vertebroplasty with polymethylmethacrylate: technique, indications, and results. Radiol Clin North Am 1998;36:533-46.

4. Bai B, Jazrawi LM, Kummer FJ, Spivak JM. The use of an injectable, biodegradable calcium phosphate bone substitute for the prophylactic augmentation of osteoporotic vertebrae and the management of vertebral compression fractures. Spine (Phila Pa 1976) 1999;24:1521-6.

5. Constantz BR, Ison IC, Fulmer MT, et al. Skeletal repair by in situ formation of the mineral phase of bone. Science 1995;267:1796-9.

6. Asaoka N, Misago M, Hirano M, Takeuchi H. Mechanical and chemical properties of the injectable calcium phosphate cement. In: Ohgushi H, Hastings
GW, Yoshikawa T, editors. Bioceramics. Vol. 12. Nara: World Scientific Publishing; 1999. p. 525-8.

7. Hirano M. Development of $\alpha$-TCP based bioactive cement. New Ceram 1993;5:55-9.

8. Kurashina K, Kurita H, Hirano M, de Blieck JM, Klein $\mathrm{CP}$, de Groot K. Calcium phosphate cement: in vitro and in vivo studies of the $\alpha$-tricalcium phosphatedicalcium phosphate dibasic-tetracalcium phosphate monoxide system. J Mater Sci Mater Med 1995;6:3407.

9. Nakano M, Hirano N, Matsuura K, et al. Percutaneous transpedicular vertebroplasty with calcium phosphate cement in the treatment of osteoporotic vertebral compression and burst fractures. J Neurosurg 2002;97(3 Suppl):287-93.

10. Yamamoto H, Mizobuchi H, Shibata T, et al. Clinical evaluation of calcium phosphate bone paste (CPC95) in orthopaedic surgery. Jpn Pharmacol Ther 1998;26:189209.

11. Ikeuchi M, Yamamoto $H$, Shibata T, Otani M. Mechanical augmentation of the vertebral body by calcium phosphate cement injection. J Orthop Sci 2001;6:39-45.

12. Nakano M, Hirano N, Ishihara H, Kawaguchi Y, Watanabe H, Matsuura K. Calcium phosphate cementbased vertebroplasty compared with conservative treatment for osteoporotic compression fractures: a matched case-control study. J Neurosurg Spine 2006;4:110-7.

13. Nakano M, Hirano N, Ishihara H, Kawaguchi Y, Matsuura K. Calcium phosphate cement leakage after percutaneous vertebroplasty for osteoporotic vertebral fractures: risk factor analysis for cement leakage. J Neurosurg Spine 2005;2:27-33.

14. Orihashi H, Sugioka Y, Fukunaga M. The Japanese society for bone and mineral research 1996 revised criteria for the diagnosis of primary osteoporosis. J Jpn Soc Bone Miner Res 1997;14:219-33.

15. Huskisson EC. Measurement of pain. Lancet 1974;2:1127-31.

16. Buchbinder R, Osborne RH, Ebeling PR, et al. A randomized trial of vertebroplasty for painful osteoporotic vertebral fractures. N Engl J Med 2009;361:557-68.

17. Kallmes DF, Comstock BA, Heagerty PJ, et al. A randomized trial of vertebroplasty for osteoporotic spinal fractures. N Engl J Med 2009;361:569-79. 
18. Wardlaw D, Cummings SR, Van Meirhaeghe J, et al. Efficacy and safety of balloon kyphoplasty compared with non-surgical care for vertebral compression fracture (FREE): a randomised controlled trial. Lancet 2009;373:1016-24.

19. Kindt-Larsen T, Smith DB, Jensen JS. Innovations in acrylic bone cement and application equipment. J Appl Biomater 1995;6:75-83.

20. Ryu KS, Park CK, Kim MC, Kang JK. Dosedependent epidural leakage of polymethylmethacrylate after percutaneous vertebroplasty in patients with osteoporotic vertebral compression fractures. J Neurosurg 2002;96(1 Suppl):56-61.

21. Cotten A, Dewatre F, Cortet B, et al. Percutaneous vertebroplasty for osteolytic metastases and myeloma: effects of the percentage of lesion filling and the leakage of methyl methacrylate at clinical follow-up. Radiology 1996;200:525-30.

22. Lieberman IH, Dudeney S, Reinhardt MK, Bell G. Initial outcome and efficacy of "kyphoplasty" in the treatment of painful osteoporotic vertebral compression fractures. Spine (Phila Pa 1976) 2001;26:1631-8.

23. Ledlie JT, Renfro M. Balloon kyphoplasty: one-year outcomes in vertebral body height restoration, chronic pain, and activity levels. J Neurosurg 2003;98(1 Suppl):36-42.
24. Lindsay R, Silverman SL, Cooper C, et al. Risk of new vertebral fracture in the year following a fracture. JAMA 2001;285:320-3.

25. Kasperk C, Hillmeier J, Nöldge G, et al. Treatment of painful vertebral fractures by kyphoplasty in patients with primary osteoporosis: a prospective nonrandomized controlled study. J Bone Miner Res 2005;20:604-12.

26. Grados F, Depriester C, Cayrolle G, Hardy N, Deramond H, Fardellone P. Long-term observations of vertebral osteoporotic fractures treated by percutaneous vertebroplasty. Rheumatology (Oxford) 2000;39:14104.

27. Uppin AA, Hirsch JA, Centenera LV, Pfiefer BA, Pazianos AG, Choi IS. Occurrence of new vertebral body fracture after percutaneous vertebroplasty in patients with osteoporosis. Radiology 2003;226:11924.

28. Fribourg D, Tang C, Sra P, Delamarter R, Bae H. Incidence of subsequent vertebral fracture after kyphoplasty. Spine (Phila Pa 1976) 2004;29:2270-6.

29. Grafe IA, Baier M, Nöldge G, et al. Calciumphosphate and polymethylmethacrylate cement in long-term outcome after kyphoplasty of painful osteoporotic vertebral fractures. Spine (Phila Pa 1976) 2008;33:1284-90. 